Research Article

\title{
Investigation of Mechanical Properties of Concrete Containing Liquid Silicone Rubber Under Axial Loads
}

\author{
Alireza Khaloo $\mathbb{D}^{1}$ and Yaser Parvin darabad $\mathbb{D}^{2}$ \\ ${ }^{1}$ Civil Engineering Department, Sharif University of Technology, Center of Excellence in Structures and Earthquake Engineering, \\ Tehran, Iran \\ ${ }^{2}$ Sharif University of Technology, International Campus, Kish Island, Iran
}

Correspondence should be addressed to Alireza Khaloo; khaloo@sharif.edu

Received 16 November 2020; Revised 19 December 2020; Accepted 22 January 2021; Published 8 February 2021

Academic Editor: Masoud Mirtaheri

Copyright (c) 2021 Alireza Khaloo and Yaser Parvin darabad. This is an open access article distributed under the Creative Commons Attribution License, which permits unrestricted use, distribution, and reproduction in any medium, provided the original work is properly cited.

\begin{abstract}
As the experts who have taken for granted the merits of utilizing the concrete as the most common material in the structural industry, there is a need to take affirmative steps to enhance the concrete's weaknesses such as the low ductility and energy absorption capacity. One possible way to improve the mechanical properties of concrete is to add liquid silicone rubber to the concrete. Silicone rubber is an elastomer (rubber-like material) composed of liquid rubber polymer and its hardener which is widely used in voltage line insulators, automotive applications, and medical devices. In order to increase the ductility and energy absorption of concrete, the liquid silicone rubber replaced a portion of mineral aggregates in concrete. HSRC (hybrid silicone rubber concrete) is a mixture of liquid silicone rubber with fresh concrete that liquid silicone rubber after 24 hours becomes a flexible solid rubber with low strength. In this paper, liquid silicone rubber was used to replace $0 \%, 2 \%, 4 \%, 8 \%, 12.5 \%, 25 \%$, and $50 \%$ of the total mineral aggregate's volume in concrete. Standard specimens were fabricated and tested. The fresh HSRC exhibited acceptable workability and lower unit weight compared to ordinary plain concrete. The uniaxial compressive strain-control test was conducted on the hardened HSRC specimens to obtain the complete stress-strain curve. The results showed that, with the increase of liquid silicone rubber in concrete, the amount of compressive strength, splitting tensile stress, and elastic modulus decreased. It was also observed that the percentage of reduction in compressive strength was greater than the percentage of reduction in tensile strength. Increasing silicone rubber concentration in HSRC changes the brittle mode of failure to ductile that demonstrated using nonlinearity indices. Unlike plain concrete, the failure state in HSRC occurs gently and uniformly and does not cause so much separation in the specimens. Larger deformation and higher toughness indices were obtained, when the silicone rubber concentration was increased.
\end{abstract}

\section{Introduction}

Silicone rubber is a widely used polymer and it is more specifically categorized as an elastomer or a rubber-like material. It is highly valued in various industries due to its chemical and mechanical resistance and stability in extreme environments. Silicone-based elastomers were first used in the 1940s in Corning Glass and General Electric because of their heat-resistant properties [1]. The simplicity of making and shaping of this material comes from the use of liquid silicone rubber, a two-part thermoset elastomer [2]. By separating the material into two parts, the uncured material takes on gel-like properties. This gel can be molded into the desired shape before it is catalyzed or cured, after which it turns into its final solid form. There are many applications for silicone rubber, including the automotive, health, medical, electrical, and other industries. Room temperature vulcanizing (RTV) silicone rubber coatings were used as electrical insulators to ameliorate their pursuant insulation strength, especially under wet conditions [3]. The use of new materials in the construction industry and maintaining the appropriate structural and architectural performance is of great functional importance [4]. Many advances have been made in creative technology in the construction industry 
and the role of ethics for sustainable development is undeniable [5]. In previous research, the effect of replacing mineral aggregates with tire-rubber particles on the properties of concrete was experimentally investigated [6]. The study revealed that the brittle nature of concrete and its low toughness was improved; however, the ultimate strength was decreased significantly. In the present study, liquid silicone rubber was used to replace mineral aggregate. Previous investigations showed the use of waste tires could improve the properties of concrete. The idea of using waste rubber as an engineering material to improve concrete properties was introduced by (Eldin and Senouci) [7]. They used tire chips and crumb rubber as aggregate in plain concrete. Investigation showed that using particle rubber instead of part of mineral aggregate causes plastic failure, more ductility, and lower compressive strength in concrete compare to control portland cement concrete. Khatib and Bayomy studied rubberized concrete using two types of tire rubber, fine crumb rubber, and coarse tire chips. Specimens were tested under compressive and flexural loads. Also, a characteristic function that quantifies the reduction in strength was developed and sensitivity analysis was performed [8]. Guoqiang $\mathrm{Li}$ et al. used waste tires in the form of fibers with various aspect ratios, in which waste tire was treated by $\mathrm{Na}(\mathrm{OH})$ before being used in concrete [9]. The recycled tire is also used in the construction of asphalt procedures and has a positive effect on its performance [10]. In other research, natural materials have been used as additives to concrete, and the structural character of deep beams made of reinforced palm kernel concrete (PKSC) was investigated by Mark Adom-Asamoah et al. [11]. The result showed that calibrated shear strength models revealed the compressive strength and the ratio of the shear span-to-total depth as significant influential parameters for correcting the inherent bias in the original deterministic shear strength models. An experimental study on the behavior of rubberized concrete mixes was conducted by Kadhim and Al-Mutairee in this research; waste tire-rubber particles were used to replace part of aggregate [12]. The static and dynamic behavior of recycled tire-rubber particle and polypropylene fibers filled concrete were investigated by Hernandez-Olivares et al. [13]. Siddiquel and Naik studied an overview of the use of scraptires in portland cement concrete [14]. Dessouki et al. studied the composites, based on Portland cement and natural rubber latex. They investigated the effective factors in the production of composite specimens such as the concentration of each component, additives incorporation, and the effect of retarding agents like sodium metasilicate. Adding retarding agent to the rubber latex increased time for molding, with no effect on the cement. The experimental result revealed that the rise in rubber latex concentration decreases compressive strength and increases tensile strength. It is concluded that cement-natural rubber molds can be used as a filling material for joints, cracks, and soil injection [15]. Toutanji studied the effect of replacement of mineral coarse aggregate with tire-rubber particle. The result showed that adding tire-rubber chips in concrete caused a reduction in compressive and flexural strengths. The compressive strength reduction was approximate twice the reduction of flexural strength. Test results revealed that specimens containing tire-rubber chips presented higher toughness and ductile failure compared to control specimens [16]. Topcu, I.B., studied the mechanical properties of rubberized concrete in terms of both size and amount of the rubber chips changes. Concrete specimens with C20 compressive strength were produced and rubbers with volume ratios of 15,30 , and $45 \%$ were added to the concrete. Tests were conducted at 28 days, and $\sigma$ - $\varepsilon$ diagrams were obtained. It was shown that plastic energy capacity began to increase when rubber chips were added to the concrete. Rubberized concrete due to its high plastic energy capacity presented higher strains compared to plain concrete [17]. Segre and Joekes investigated the mechanical properties of rubberized concretes with and without silica fume. The research concluded that a large reduction in strength and elastic modulus values resulted when rubber content is increased. Adding the silica fume into the concrete mixture improved the mechanical properties of the rubberized concretes and decreased the strength loss. Previous findings show that the properties of concrete containing tire-rubber particles are affected by type, size, content, shape, and the procedure of mixing the rubber into the concrete [18]. The comparative study on the flexural behavior of rubberized reinforced concrete beams conducted by Alasmari et al. revealed an ameliorated performance with the use of the hybrid beams [19]. The effect of using waste tire rubber and nanomaterial in the construction of concrete curbs has been studied by Komaki et al. The results showed a positive effect on durability and abrasion resistance [20]. In this research study, hybrid silicone rubber concrete (HSRC) properties using mechanical tests on the different percent of liquid silicone rubber to the total mineral aggregate's volume in concrete at different ages are investigated. The experimental observations and subsequent explanations of HSRC behavior under compressive loading are presented. HSRC is expected to have high flexibility. Flexible materials are widely used in industry [21]. Flexibility has a great impact on the behavior of structures and improves their seismic performance in both steel and RC structures [22].

\section{Experimental Program}

In order to study the mechanical properties of HSRC, specimens of a cylindrical shape $(15 \times 30 \mathrm{~cm})$ were fabricated and tested. These specimens were different in the content of liquid silicone rubber as a portion of total aggregates in concrete.

2.1. Materials. Constituent materials for concrete mixes included type II Portland cement corresponding to ASTM C150 [23] requirements, gravel with a maximum size of $19 \mathrm{~mm}$ as coarse aggregate, sand with $4.75 \mathrm{~mm}$ maximum size as fine aggregate, and liquid silicone rubber RTV. The word RTV is abbreviated from the three words "room temperature vulcanizing." Generally, silicone rubber is used for molding and sculpting. The liquid silicone rubber RTV contains two parts, One part is liquid silicone rubber, and 
the other is hardener. After combining these two parts together, the resulting mixture turns into solid silicone rubber after 18 to 24 hours. The hardener should be used according to the manufacturer's instructions. In this study, liquid silicone rubber produced by JINGYI Company was used. Silicone rubber specifications are summarized in Table 1. These specifications are based on the factory test. The properties of fine and coarse aggregates were determined according to ASTM C127, 128, 129 standard test methods. Gradation curves of sand and gravel aggregates are presented in Figure 1. The properties of aggregates are presented in Table 2. The specific gravity of the Portland cement type II was $3.17 \mathrm{~g} . \mathrm{cm}^{3}$.

\subsection{Concrete Specimens Mixtures and Manufacturing.} The experimental setup and specimen mix design content are summarized in Tables 3 and 4, respectively. In order to evaluate the effect of the amount of liquid silicone rubber on the properties of concrete in low and high volume values, the range of mineral aggregates replacement was considered between 0 and $50 \%$ by the total volume of aggregates. Also to study the process of increasing the amount of silicone rubber and its effect on the mechanical properties of concrete, the percentages of liquid silicone rubber volume to the total mineral aggregate volume include $0,2,4,8,12.5,25$, and 50 percent. The weight of fine and coarse aggregates was adjusted by the percentage of silicone rubber replacements. A normal Portland cement concrete, with a $35 \mathrm{MPa}$ targeted compressive strength, was designed as the control mix following ACI standard 211.1-81 [24]. The water to cement ratio is considered to be 0.4 and two values for gravel to sand ratio of 1.1 and 0.7 are utilized. Polycarboxylate based superplasticizer was used to increase workability. Specimens were remolded 24 hours after casting and then cured in water until 24 hours before testing. Increasing the amount of sand in concrete improves the mechanical properties of fiber-reinforced concrete [25]. To determine the influence of $\mathrm{G} / \mathrm{S}$ (gravel to sand ratio) changes on the mechanical properties of HSRC, two ratios of $\mathrm{G} / \mathrm{S}=0.7$ and 1.1 were considered. Water absorption of aggregates before making specimens was considered in the concrete mix design. Seven mix designs were used and the proportions are presented in Table 4. For the labeling of concrete specimens, in terms of the ratio of the coarse to fine aggregate, two concrete grades, LF (low mineral fine aggregate with $\mathrm{G} / \mathrm{S}=1.1$ ) and HF (high mineral fine aggregate with $\mathrm{G} / \mathrm{S}=0.7$ ), were used. Citing an example, the HF-G4S4 mixture indicates that liquid silicone rubber was replaced by $4 \%$ of coarse aggregate and $4 \%$ of fine aggregate of the volume using high sand content.

2.3. Test Methods. To evaluate the characteristics of fresh HSRC, slump and unit weight were measured in accordance to ASTM C143 [26] and ASTM C138 [27], respectively. A compressive strain-control test was performed on hardened specimens to obtain the complete stress-strain curves. The test was conducted by a universal testing machine with $0.05 \mathrm{~mm} / \mathrm{sec}$ rate of loading. Compressive tests were performed at 28 days and the test setup is shown in Figure 2. For all specimens, the tangential modulus of elasticity at $40 \%$ of the ultimate stress on the elastic region of the stress-strain diagrams was determined. Also, the splitting tensile strength of the HSRC specimens was determined on the cylindrical specimens $(15 \times 30 \mathrm{~cm})$ according to ASTM C469.

\section{Experimental Results and Discussion}

3.1. Properties of Fresh Concrete. The slump and unit weight of the fresh concrete with respect to silicone rubber content are presented in Figure 3. The workability of fresh concrete is affected by the interactions of liquid silicone rubber and mineral aggregates. As shown in Figure 3(a), the slump of the specimens decreased when liquid silicone rubber content is increased. LF specimens exhibited a lower slump compared to those of HF specimens with the same silicone rubber concentration. The test result revealed that the fresh HSRC with liquid silicone rubber content up to $50 \%$ exhibits acceptable workability in terms of fabricating, placement, and finishing. As shown in Figure 3(b), the unit weight of the HSRC reduced from 2390 to $2070 \mathrm{~kg} \cdot \mathrm{m}^{3}$, depending on the silicone rubber content.

\subsection{Hardened Concrete Properties}

3.2.1. Visual Observation of HSRC Specimen Behavior. Duration to concrete failure is defined as failure duration [1]. In plain concrete, failure is abrupt and explosive; however, in HSRC specimen, failure duration is gradual and longer, and also failure is not explosive because HSRC becomes flexible by the addition of silicone rubber content. As shown in Figure 4, white color particles are silicone rubber, which are relatively well distributed in concrete. Figures 5 and 6 show that the stress-strain curves of HSRC specimens withstand loads beyond the peak load like flexible materials that are referred to as postpeak strength. The failure state in control specimens (without silicone rubber) was abrupt with loud sound and the failure state is accompanied by separation of pieces from the specimens. HSRC specimen failure state was accompanied by less separation of pieces from the specimen compared to control concrete specimen; as shown in Figure 7, the failure state was not explosive. HSRC specimens exhibited large deformations compared to control specimens and cracks propagated relatively uniformly and gradually in HSRC specimens. Well propagated cracks and dispersed failures for HSRC specimens were observed in comparison with plain concrete. As shown in Figure 3, the particle of silicone rubber particles distributed in concrete is clearly visible.

The lateral deformations of HSRC specimens are larger than those of plain concrete specimens because of the porosity due to the substitution of silicone rubber with mineral aggregate and also due to higher Poisson's ratio of HSRC than that for plain concrete. It should be noted that the behavior of HSRC is not perfectly elastic, since Poisson's ratio is not constant for the concrete composite during ascending loading process. Poisson's ratio increases as the silicone rubber content is increased and the behavior of HSRC tends to behave as a plastic material. As shown in 
TABLE 1: Silicone rubber specifications.

\begin{tabular}{lccc}
\hline Property & Minimum value & Maximum value & SI unit \\
\hline Atomic volume (average) & 0.0035 & 0.0055 & 2.3 \\
Density & 1.1 & 2 & $\mathrm{Mg} \cdot \mathrm{m}^{3}$ \\
Bulk modulus & 1.5 & 30 & $\mathrm{GPa}$ \\
Compressive strength & 10 & 5.5 & $\mathrm{MPa}$ \\
Elastic limit & 2.4 & 5.23 & $\mathrm{MPa}$ \\
Endurance limit & 2.28 & 0.7 & $\mathrm{MPa}$ \\
Fracture toughness & 0.03 & 5.5 & $\mathrm{MPa} \cdot \mathrm{m}^{1.2}$ \\
Modulus of rupture & 2.4 & 0.49 & $\mathrm{MPa}$ \\
Poisson's ratio & 0.47 & 0.02 & $\mathrm{GPa}$ \\
Shear modulus & 0.0003 & 5.5 & $\mathrm{MPa}$ \\
Tensile strength & 2.4 & 0.05 & $\mathrm{GPa}$ \\
Young's modulus & 0.001 & 200 & $\mathrm{~K}$ \\
Glass temperature & 150 & 560 & $\mathrm{~K}$ \\
Maximum service temperature & 500 & 225 & $\mathrm{~K}$ \\
Minimum service temperature & 200 & 1300 & $\mathrm{~J} \cdot \mathrm{kg} \cdot \mathrm{K}$ \\
Specific heat & 1050 & 2.55 & $\mathrm{~W} \cdot \mathrm{m} \cdot \mathrm{K}$ \\
Thermal conductivity & 0.2 & 300 & $10^{-6} \cdot \mathrm{K}$ \\
Thermal expansion & 250 & & \\
\hline
\end{tabular}

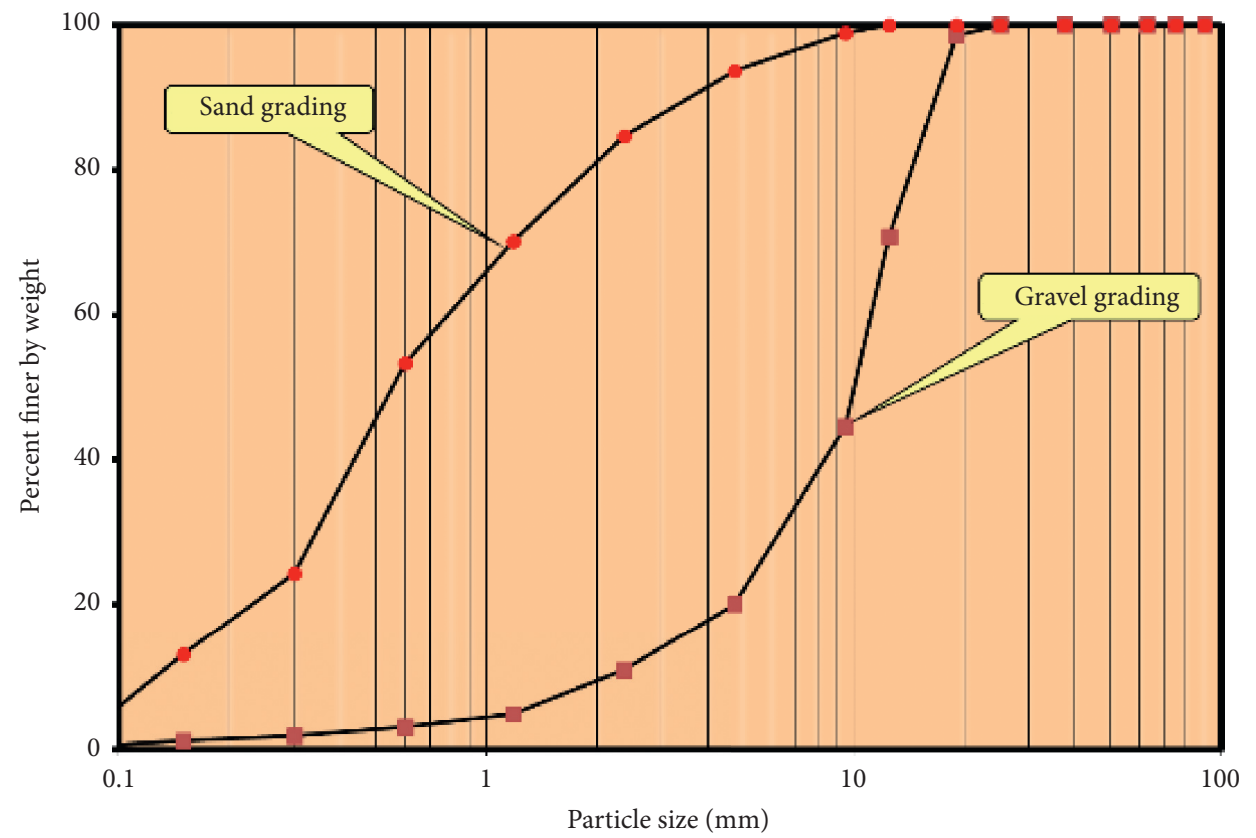

FIgURE 1: Gradation of mineral aggregates.

TABle 2: Properties of aggregates.

\begin{tabular}{lcccc}
\hline Aggregate type & Specific gravity & Water absorption $(\%)$ & Fineness modulus & Unit weight $\left(\mathrm{kg} \cdot \mathrm{m}^{3}\right)$ \\
\hline Coarse aggregate & 2.63 & 2.69 & NA & 1709.6 \\
Fine aggregate & 2.69 & 5.16 & 4.38 & 1729 \\
\hline
\end{tabular}

Figure 5, considerable lateral deformations were observed in HSRC specimens at the end of the loading process.

3.2.2. Stress-Strain Response. The stress-strain curves of HSRC specimens with different mixtures and various concentrations of silicone rubber are shown in Figures 6-8.
The curves indicate that the HSRC specimens are more ductile compared to those for plain concrete specimens. The behavior of LF-G25S25, HF-G25S25, LF-G50S50, and HFG50S50 specimens is like the nonlinear material and postpeak strength is clearly visible. To compare the nonlinearity between HSRC specimens and control specimens, the nonlinearity index was expressed as the ratio of the slope of 
TABLe 3: Experimental program.

\begin{tabular}{lccccc}
\hline $\begin{array}{l}\text { Specimen } \\
\text { designation }\end{array}$ & $\begin{array}{c}\text { Liquid silicone rubber content } \\
(\%) \text { by total aggregates }\end{array}$ & $\begin{array}{c}\text { Fine } \\
\text { aggregate (\%) }\end{array}$ & $\begin{array}{c}\text { Coarse } \\
\text { aggregate (\%) }\end{array}$ & $\begin{array}{c}\text { Superplasticizer to } \\
\text { cement ratio (\%) }\end{array}$ & $\begin{array}{c}\text { Replicates of compressive } \\
\text { test (at 28 days) }\end{array}$ \\
\hline LF-G0S0 & 0 & 100 & 100 & 2 & 3 \\
LF-G1S1 & 1 & 99 & 99 & 2 & 3 \\
LF-G2S2 & 2 & 98 & 98 & 2 & 3 \\
LF-G4S4 & 4 & 96 & 96 & 2 & 3 \\
LF-G12.5S12.5 & 12.5 & 87.5 & 87.5 & 2 & 3 \\
LF-G25S25 & 25 & 75 & 75 & 2 & 3 \\
LF-G50S50 & 50 & 50 & 50 & 2 & 3 \\
\hline HF-G0S0 & 0 & 100 & 100 & 2 & 3 \\
HF-G1S1 & 1 & 99 & 99 & 2 & 3 \\
HF-G2S2 & 2 & 98 & 98 & 2 & 3 \\
HF-G4S4 & 4 & 96 & 96 & 2 & 3 \\
HF-G12.5S12.5 & 12.5 & 87.5 & 87.5 & 75 & 3 \\
HF-G25S25 & 25 & 75 & 50 & 2 & 3 \\
HF-G50S50 & 50 & 50 & & 2 & 3 \\
\hline
\end{tabular}

TABLE 4: Concrete mixture proportions.

\begin{tabular}{|c|c|c|c|c|c|c|c|c|}
\hline Specimen & $\begin{array}{l}\text { Water } \\
\text { (lit) }\end{array}$ & $\begin{array}{l}\text { Cement } \\
\left(\mathrm{kg} / \mathrm{m}^{3}\right)\end{array}$ & $\begin{array}{c}\text { Gravel. Sand } \\
\text { G/S }\end{array}$ & $\begin{array}{l}\text { Liquid silicone rubber } \\
\qquad\left(\mathrm{kg} / \mathrm{m}^{3}\right)\end{array}$ & $\begin{array}{l}\text { Coarse } \\
\text { aggregate } \\
\left(\mathrm{kg} / \mathrm{m}^{3}\right)\end{array}$ & $\begin{array}{c}\text { Fine } \\
\text { aggregate } \\
\left(\mathrm{kg} / \mathrm{m}^{3}\right)\end{array}$ & $\begin{array}{l}\text { Moisture of gravel } \\
\text { (\%) }\end{array}$ & $\begin{array}{c}\text { Moisture of sand } \\
(\%)\end{array}$ \\
\hline LF-G0S0 & 224 & 350 & & 0.00 & 942.86 & 857.14 & 3 & 4 \\
\hline LF-G1S1 & 231 & 350 & & 12.67 & 933.43 & 848.57 & 3 & 3.2 \\
\hline LF-G2S2 & 240 & 350 & & 25.34 & 924.00 & 840.00 & 2 & 3 \\
\hline LF-G4S4 & 204 & 350 & 1.1 & 50.69 & 905.14 & 822.86 & 4 & 5 \\
\hline LF-G12.5S12.5 & 216 & 350 & & 158.40 & 825.00 & 750.00 & 3 & 4 \\
\hline LF-G25S25 & 187 & 350 & & 316.79 & 707.14 & 642.86 & 5 & 5 \\
\hline LF-G50S50 & 184 & 350 & & 633.59 & 471.43 & 428.57 & 4 & 4.5 \\
\hline HF-G0S0 & 218 & 350 & & 0.00 & 741.16 & 1058.80 & 4 & 4 \\
\hline HF-G1S1 & 238 & 350 & & 12.66 & 733.75 & 1048.21 & 4 & 1.3 \\
\hline HF-G2S2 & 240 & 350 & & 25.31 & 726.34 & 1037.62 & 3.2 & 2 \\
\hline HF-G4S4 & 236 & 350 & 0.7 & 50.62 & 711.51 & 1016.45 & 3.2 & 2.3 \\
\hline HF-G12.5S12.5 & 226 & 350 & & 158.19 & 648.52 & 926.45 & 3 & 3.1 \\
\hline HF-G25S25 & 224 & 350 & & 316.39 & 555.87 & 794.10 & 2.1 & 3 \\
\hline HF-G50S50 & 204 & 350 & & 632.77 & 370.58 & 529.40 & 2 & 2.5 \\
\hline
\end{tabular}

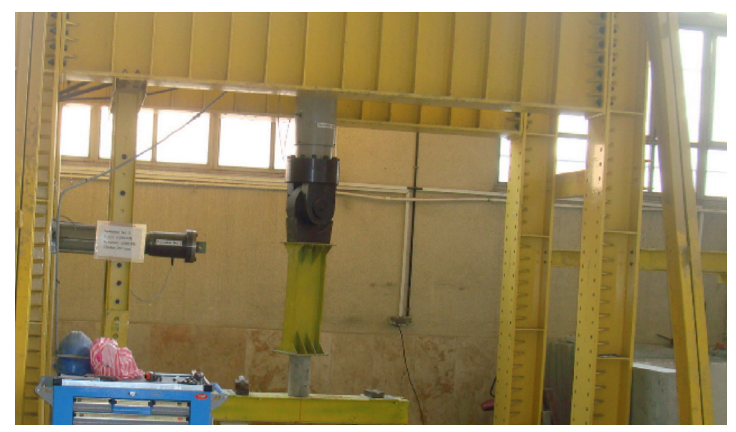

Figure 2: Test setup.

the line connecting the origin to the point at $40 \%$ of ultimate stress on the stress-strain curve, to the slope of the line from the origin to the ultimate stress as shown in Figure 9(a). Based on the results presented in Figure 9(b), for both LF and HF specimens, it can be seen that, with increasing the amount of silicone rubber from 0 to $25 \%$, nonlinearity index has an increasing trend, but with the increase in the amount of silicone rubber, the nonlinearity index has decreased by $25 \%$. A comparison between the investigated mixtures indicates that the HF specimen's behavior is a little more 


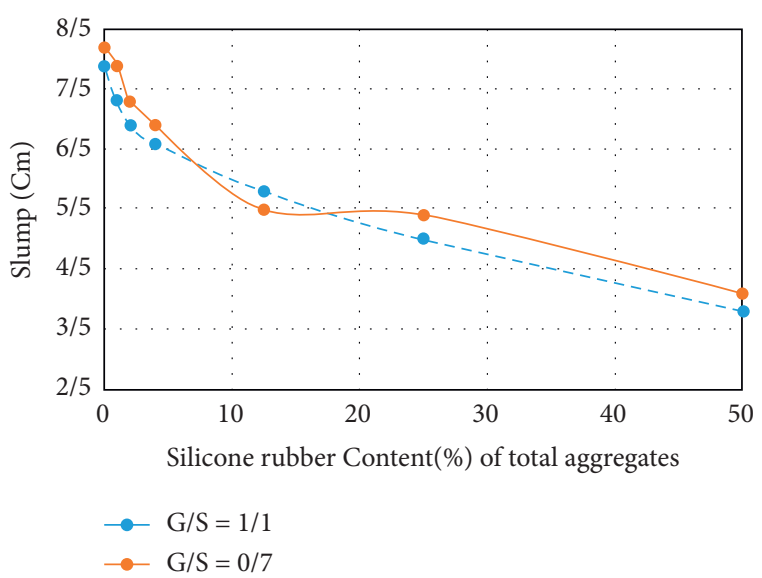

(a)

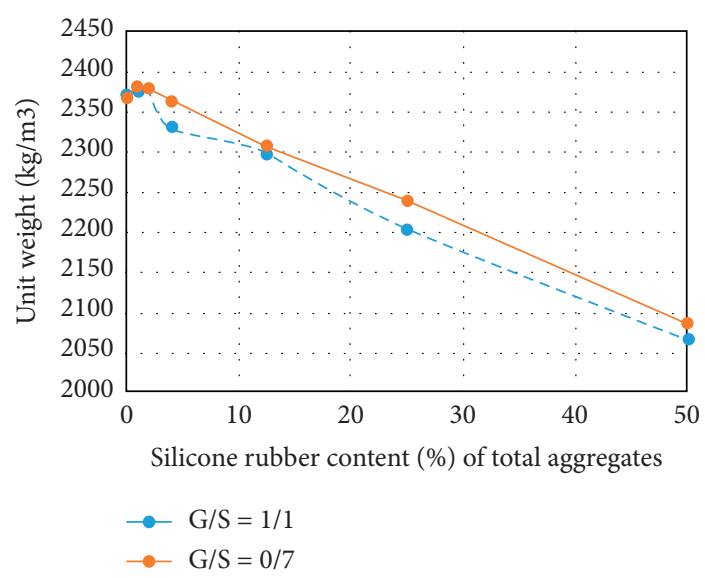

(b)

Figure 3: Properties of fresh HSRC. (a) Slump. (b) Unit weight of fresh HSRC.
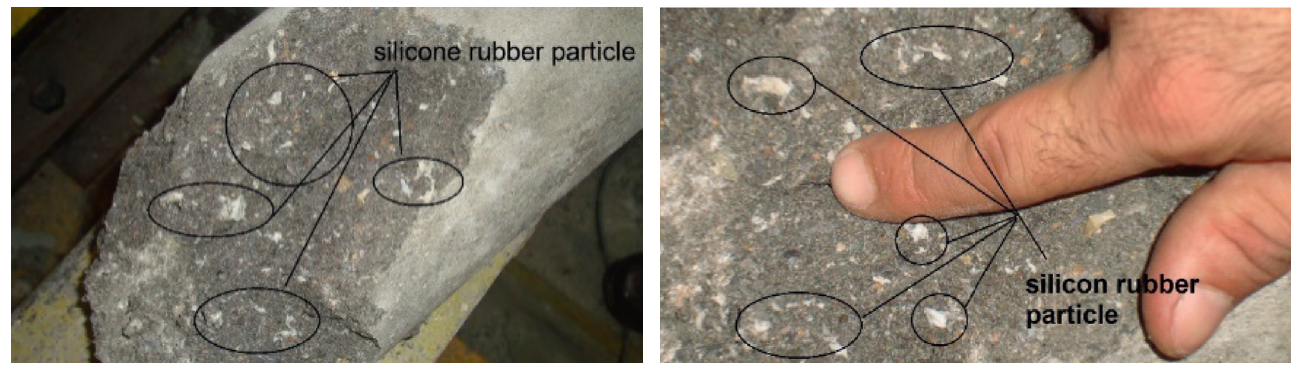

FIGURE 4: Silicone rubber particles distributed in HSRC specimens.

nonlinear compared to those for LF specimens with the same silicone rubber concentration. The substitution of silicone rubber for mineral aggregates caused more uniform crack development and crack propagation, compared to control specimens. The stress-strain curves indicated that HSRC specimens exhibit larger deformation compared to control specimens. In the stress-strain curve, the slope of the tangent line at the point that stress is $40 \%$ of the ultimate stress is expressed as $E_{t}$ and obtained from the following equation:

$$
E_{t}=\frac{\mathrm{d} \sigma}{\mathrm{d} \varepsilon} \text { at } 40 \% \text { of ultimate stress, }
$$

where $\mathrm{d} \sigma$ in and $\mathrm{d} \varepsilon$ are stress and strain changes at the point that stress is $40 \%$ of the ultimate stress. $E_{t}$ is a suitable factor to indicate the stiffness attributed to elastic deformation in HSRC specimens. $E_{t}$ for different mixtures and silicone rubber concentrations are given in Table 5. A decrease in $E_{t}$ for HSRC specimens implies larger deformations. A comparison of the results in Table 5 indicates that HF specimens result in higher $E_{t}$ than LF specimens for the same silicone rubber concentration.
3.2.3. Compressive and Tensile Strengths. As shown in Table 5 , an increase in silicone rubber concentration of HSRC specimens decreased the ultimate compressive strength and tensile splitting strength. The maximum strength reduction for $50 \%$ silicone rubber replacement is $82 \%$ percent in average according to Table 5. As shown in Figure 10(a), the ultimate compressive and splitting tensile strength of $\mathrm{HF}$ specimens are more than those of LF specimens for the same silicone rubber concentration. While reducing ultimate strength, SHRC provides ductile behavior and failure in HSRC specimens.

3.2.4. Toughness of HSRC. Toughness is the ability of the material to absorb energy by plastic deformation before rupturing. The toughness of HSRC was determined by calculating the area under the stress-strain curve up to a point corresponding to $80 \%$ of maximum stress in the postpeak region. The toughness index $T_{i}$, is expressed as the ratio of the area under the stress-strain curve up to $80 \%$ of the maximum stress in the postpeak region $T_{80 \%}$, to the area 

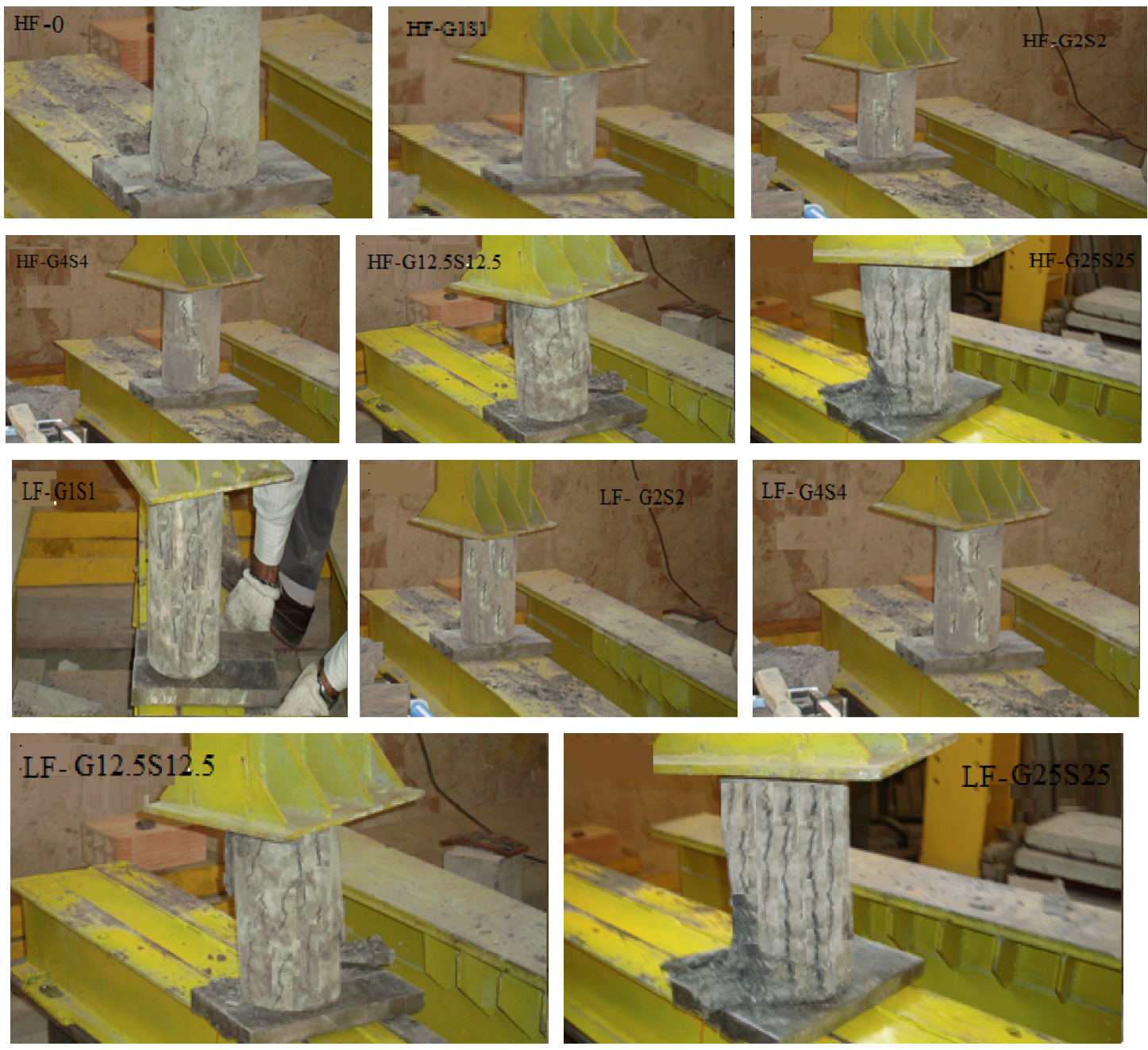

FIGURE 5: Stress-strain curve of HF specimens at 28 days. (a) Stress-strain diagrams of all HF specimens at 28 days. (b) Stress-strain diagrams of HF specimens with low content of silicone rubber at 28 days. (c) Stress-strain diagrams of HF specimens with a high content of silicone rubber at 28 days.

under the stress-strain curve up to the maximum stress $T_{100 \%}$, as shown in Figure 11(a). Choosing $80 \%$ of maximum stress is due to the fact that strength reduced to this amount is an acceptable level of service load. The toughness index $T_{i}$ is defined as follows:

$$
T_{i}=\frac{\operatorname{Area}\left(T_{80 \%}\right)}{\operatorname{Area}\left(T_{100 \%}\right)}
$$

where $T_{i}$ for HSRC specimens with various concentrations of silicone rubber are presented in Figure 11(b). As shown in Figure 11(b), $T_{i}$ showed an upward trend with an increase in silicone rubber concentration in concrete up to $25 \%$ and an amount of $50 \%$ silicone rubber concentration $T_{i}$ showed a downward trend. Maximum $T_{i}$ was obtained for LF-C25F25 and HF-C25F25 mixtures. Maximum $T_{i}$ was obtained for specimen HF with $25 \%$ of silicone rubber concentration.

\section{Reduction Factor (RF) for Hardened HSRC Specimens}

The test results of HSRC specimens showed that the amount of silicone rubber content plays a decisive role in the mechanical property of this type of concrete. Therefore, by using the amount of rubber, a function can be extracted that expresses the properties of HSRC based on the percentage of silicone rubber content in the mixture. The RF function is defined as the ratio of the compressive or tensile strength and modulus of elasticity of silicone rubber-containing 


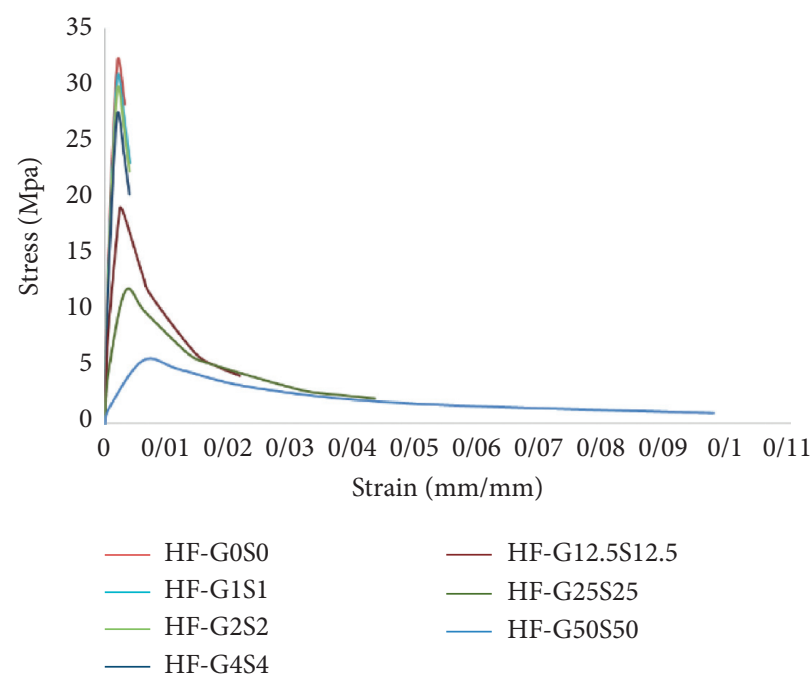

(a)

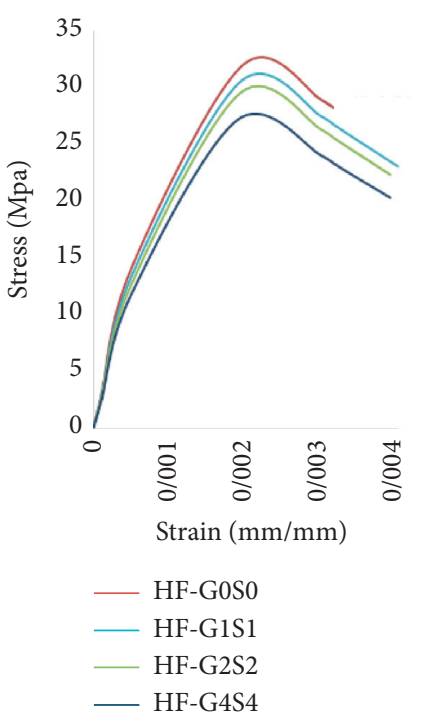

(b)

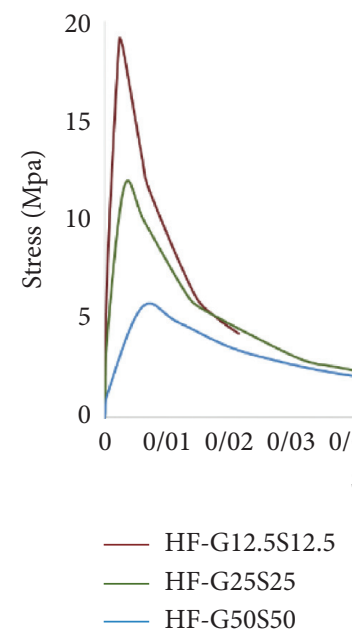

(c)

FiguRE 6: Stress-strain curve of LF specimens at 28 days. (a) Stress-strain diagrams of all LF specimens at 28 days. (b) Stress-strain diagrams of LF specimens with low content of silicone rubber at 28 days. (c) Stress-strain diagrams of LF specimens with a high content of silicone rubber at 28 days.

specimens to a silicone rubber-free control. When the goal is to determine the compressive or tensile strength of the specimen, the function is called the Fc-RF or Ft-RC, respectively, and if the goal is to determine the modulus of elasticity, it is called the Et-RF. The RF value will be 1 when the percentage of silicone rubber is zero (control specimen) and the value of RF decreases with increasing silicone rubber content. Based on similar studies performed on rubber concrete by Khatib and Bayomi (1999) [3], the following general formula is used to calculate the percentage of the reduction value:

$$
\mathrm{RF}=a+b(1-R)^{m} .
$$

$\mathrm{RF}$ is the reduction factor and RF will be equal to 1 when $R$ is $0 \%$. The following condition should be considered in the above equation:

$$
a+b=1 .
$$

The value of the RF varies between 1 and 0 , and $R$ is defined as rubber content in a volumetric ratio of total aggregate volume; also, a, b, $\mathrm{m}$ are numeric parameters. The Fc-RF function is introduced as the compressive strength reduction factor, and the Et-RF function is introduced as the elastic modules reduction factor. Numerical analysis was performed on the experimental data to obtain the parameters $\mathrm{a}, \mathrm{b}, \mathrm{m}$ and also the R-square test was used to check the 


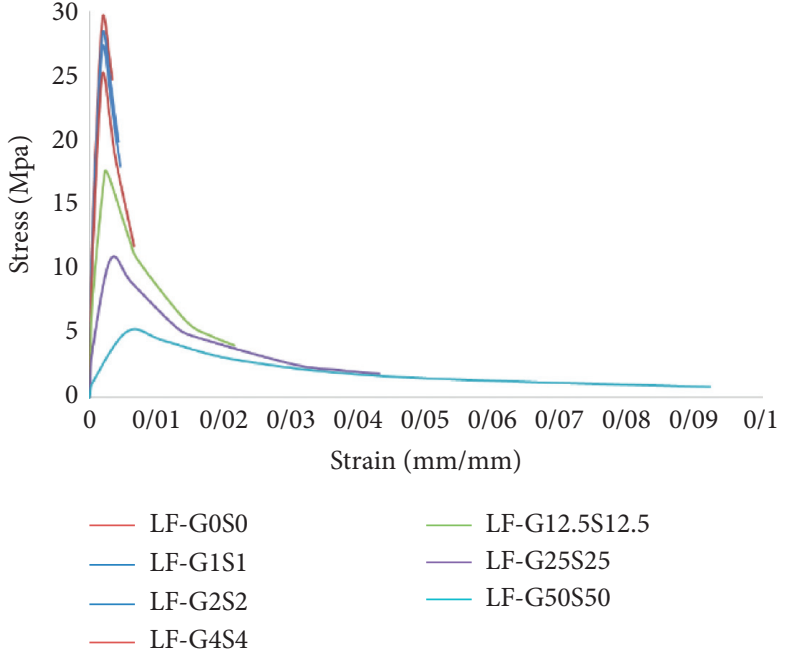

(a)

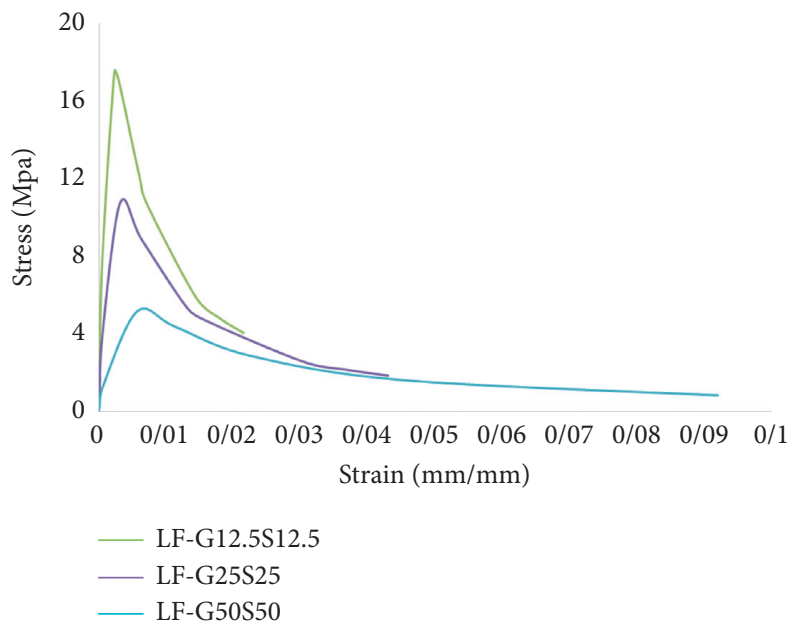

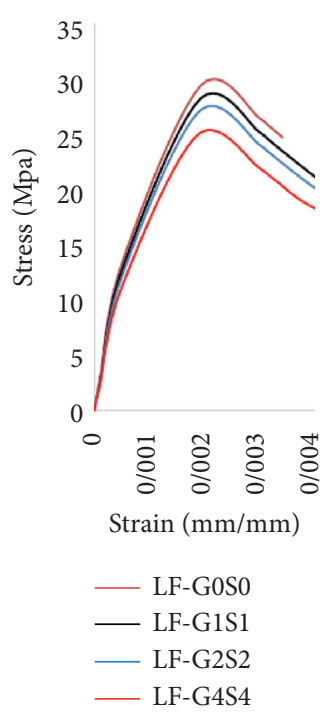

(b)

(c)

Figure 7: Failure types of HSRC specimens under compression test.

error rate of the extracted functions. The results are shown in Table 6. Comparison of the extracted RF-functions results and HSRC specimens test results is presented in Figure 12.

\section{Conclusions and Recommendations}

Increasing silicone rubber content in fresh HSRC specimens resulted in lower unit weights compared to control plain concrete. The workability of HSRC specimens was reduced by increasing liquid silicone rubber concentration. For maximum silicone rubber replacement of $50 \%$ by total volume of aggregates, HSRC provided acceptable workability. With increasing the amount of silicone rubber in concrete, a decrease in concrete strength was observed. There is an $83 \%$ reduction in compressive strength and $70 \%$ reduction in splitting tensile strength when the amount of silicone rubber is equal to $50 \%$ (LF-G50S50 and HFG50S50). The nonlinearity indices and compressive toughness increased when silicone rubber concentration increased for all specimens up to $25 \%$ and nonlinearity indices and compressive toughness decreased for values greater than $25 \%$ silicone rubber. HSRC specimens exhibited more ductile behavior than plain concrete specimens under the compression load, the failure state in HSRC specimens is not brittle, and the failure does not occur suddenly like plain concrete. As the amount of silicone rubber in the specimens increased, the crushing of the specimens became slower and accompanied by less sound and the behavior became more ductile. To compare the effect of the fine to coarse aggregate ratio, it is worth mentioning that HF specimens $(\mathrm{G} / \mathrm{S}=0.7)$ exhibited greater compressive strength than $\mathrm{LF}(\mathrm{G} / \mathrm{S}=1.1)$ specimens with the same total silicone rubber concentration. This suggests that compressive strength increases with increasing fine aggregates. These findings show that although the mechanical properties of HSRC are mainly dependent on the total rubber content, the ratio of coarse to fine particles can be used for behavior adjustment. 


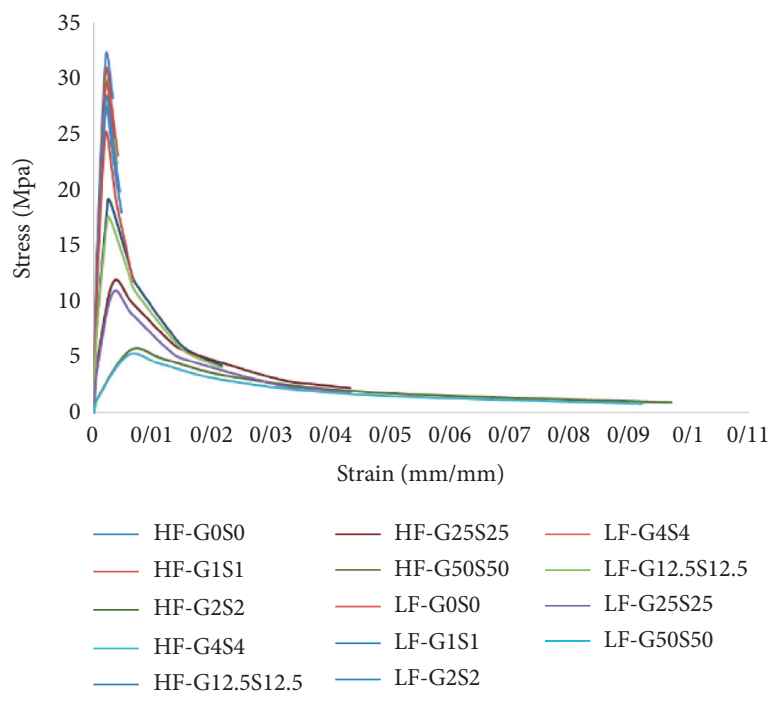

(a)

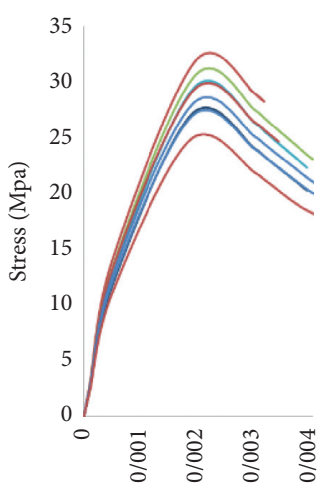

Strain $(\mathrm{mm} / \mathrm{mm})$

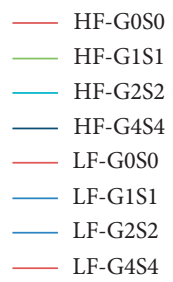

(b)

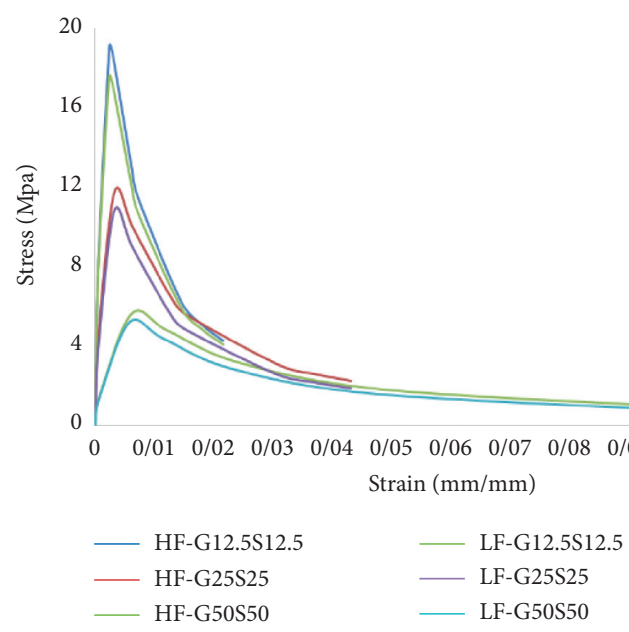

(c)

FIGURE 8: Stress-strain curve of HF\&LF specimens at 28 days. (a) Stress-strain diagrams of all HF\&LF specimens at 28 days. (b) Stress-strain diagrams of HF\&LF specimens contain a low content of silicone rubber at 28 days. (c) Stress-strain diagrams of HF\&LF specimens contain a high content of silicone rubber at 28 days.

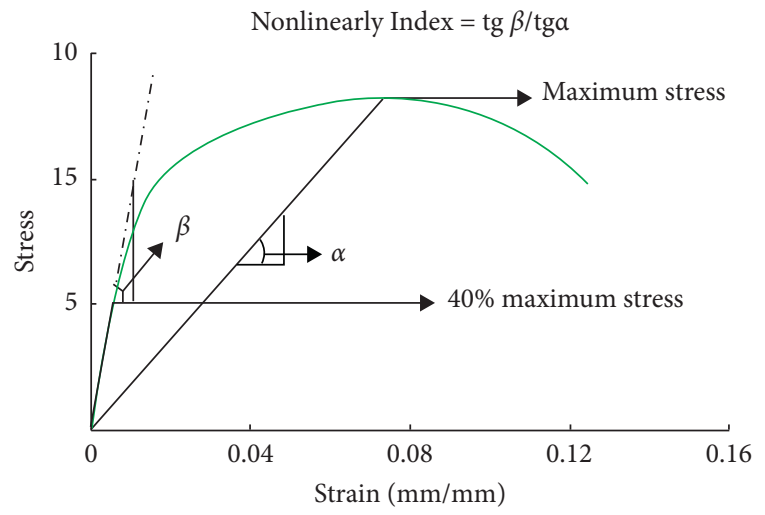

(a)

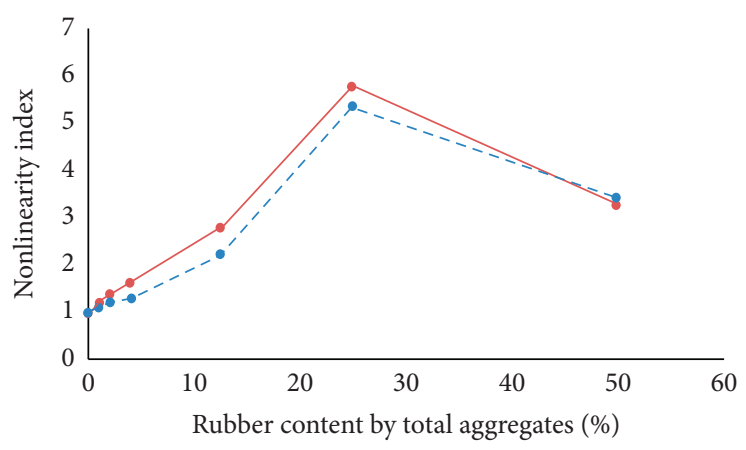

$\because \mathrm{G} / \mathrm{S}=0.7$

- $\mathrm{G} / \mathrm{S}=1.1$

Figure 9: (a) Evaluation of nonlinearity index. (b) Nonlinearity index for HSRC specimens at 28 days. 
TABle 5: Maximum stress and tangential moduli of elasticity and tensile splitting stress for HSRC at 28 days.

\begin{tabular}{lcccc}
\hline Concrete mixture & Total rubber content $(\%)$ & Fc-max $(\mathrm{MPa})$ & Et $(\mathrm{GPa})$ & 2.67 \\
LF-G0S0 & 0 & 29.35 & 2.52 & 2.90 \\
LF-G1S1 & 1 & 28.14 & 2.39 & 2.79 \\
LF-G2S2 & 2 & 27.02 & 2.18 & 2.59 \\
LF-G4S4 & 4 & 24.86 & 1.69 & 2.52 \\
LF-G12.5S12.5 & 12.5 & 17.52 & 0.84 & 1.84 \\
LF-G25S25 & 25 & 10.70 & 0.25 & 1.39 \\
LF-G50S50 & 50 & 5.19 & 2.80 & 0.84 \\
\hline HF-G0S0 & 0 & 32.00 & 2.63 & 3.64 \\
HF-G1S1 & 1 & 30.58 & 2.44 & 3.40 \\
HF-G2S2 & 2 & 29.53 & 2.27 & 3.13 \\
HF-G4S4 & 4 & 27.22 & 1.67 & 2.98 \\
HF-G12.5S12.5 & 12.5 & 19.16 & 0.99 & 2.29 \\
HF-G25S25 & 25 & 11.70 & 0.27 & 1.78 \\
HF-G50S50 & 50 & 5.64 & & 1.09 \\
\hline
\end{tabular}

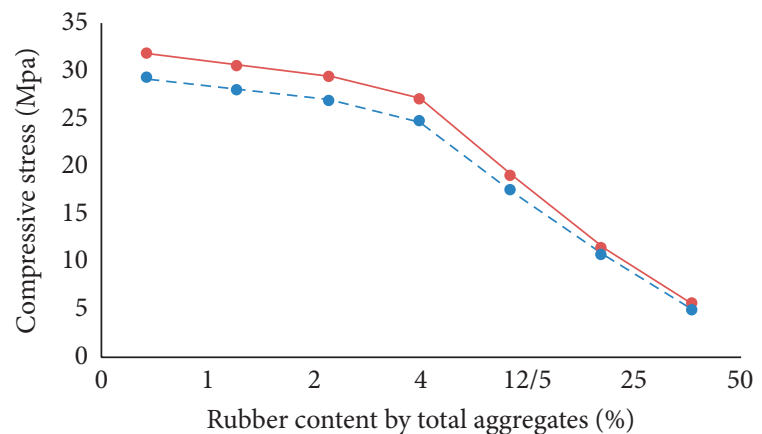

$\rightarrow \mathrm{G} / \mathrm{S}=0.7$

$\rightarrow-\mathrm{G} / \mathrm{S}=1.1$

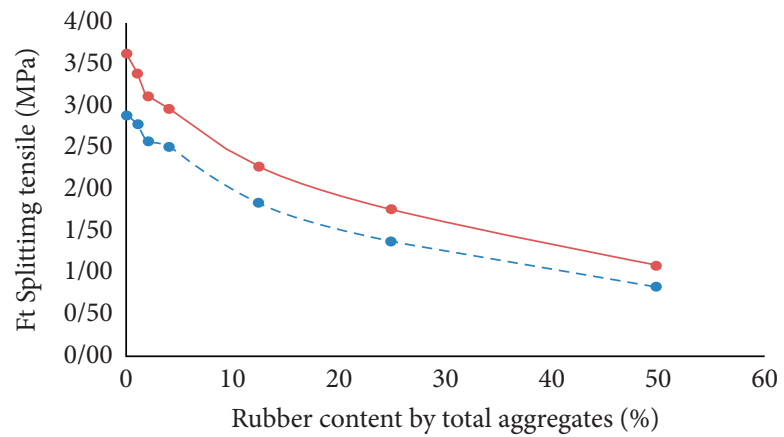

$\rightarrow \mathrm{G} / \mathrm{S}=0.7$

$\rightarrow \mathrm{G} / \mathrm{S}=1.1$

(a)

(b)

Figure 10: (a) Maximum compressive stress of HSRC specimens at 28 days. (b) Maximum tensile splitting stress of HSRC specimens at 28 days.

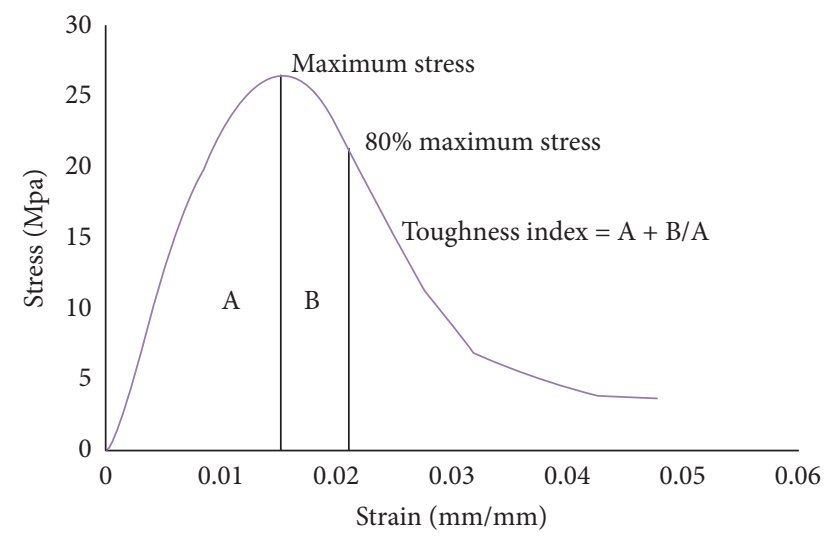

(a)

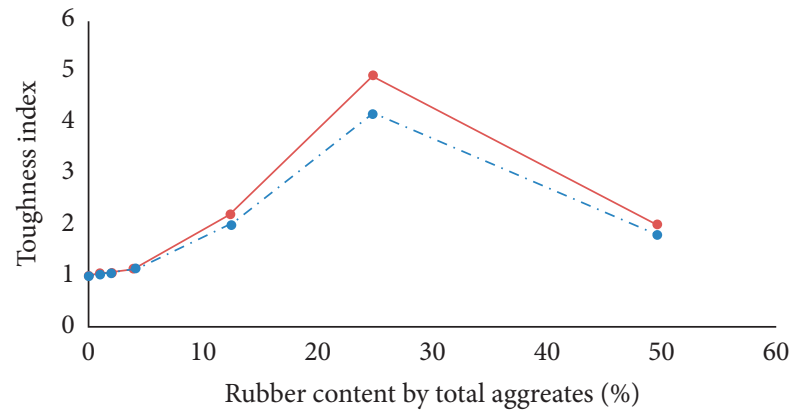

- $\mathrm{G} / \mathrm{S}=0.7$

$\rightarrow \mathrm{G} / \mathrm{S}=1.1$

(b)

FIGURE 11: (a) Evaluation of toughness index. (b) The toughness index value for HSRC specimens at 28 days. 
TABLE 6: Parameter of reduction function for HSRC specimens at 28 days.

\begin{tabular}{lccc}
\hline Model parameter & & $\begin{array}{c}\text { Concrete property } \\
\text { Splitting tensile strength (Ft) }\end{array}$ & Modulus of elasticity (Et) \\
\hline A & 0.12 & 0.25 & 0.22 \\
B & 0.88 & 0.75 & 0.78 \\
M & 4.1 & 3.87 & 6.86 \\
R-square & 0.94 & 0.95 & 0.85 \\
\hline
\end{tabular}

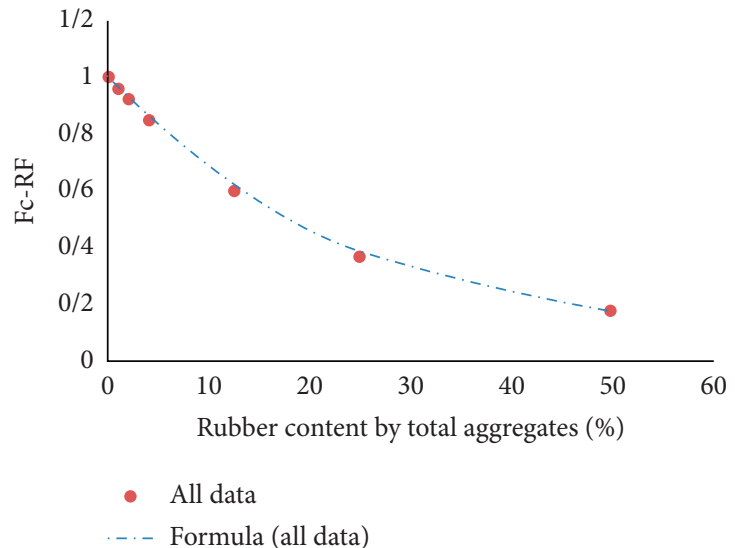

(a)

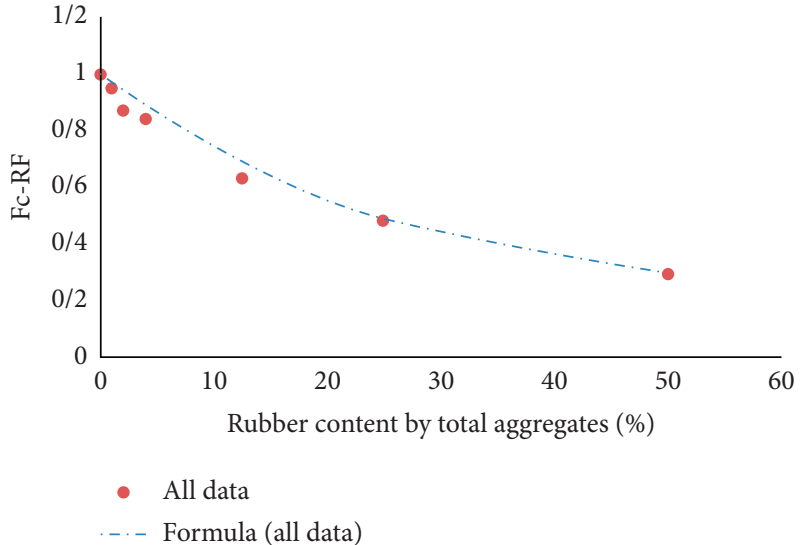

(b)

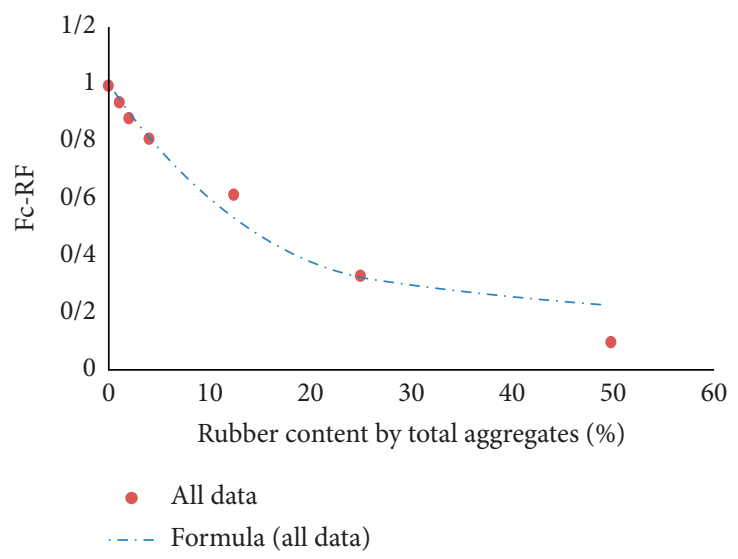

(c)

Figure 12: (a) Compressive strength reduction factor, (b) splitting tensile strength reduction factor, and (c) elastic modulus reduction factor of all types of rubberized concrete containing different silicone rubber content.

\section{Data Availability}

The results are obtained from the laboratory, and any data will be made available if needed.

\section{Disclosure}

This work forms a part of the Ph.D. dissertation of the second author.

\section{Conflicts of Interest}

The authors declare that there are no conflicts of interest regarding the publication of this manuscript.

\section{Acknowledgments}

The authors are grateful for the support provided by the Strong Floor Lab Personnel at Sharif University of Technology in conducting this research. Partial financial support was provided by the Ministry of Energy (Golestan Regional Water Authority), Iran National Science Foundation (INSF), and Center of Excellence in Composite Structures and Seismic Strengthening.

\section{References}

[1] S. Hamdani, C. Longuet, D. Perrin, J.-M. Lopez-Cuesta, and F. Ganachaud, "Flame retardancy of silicone-based materials," 
Polymer Degradation and Stability, vol. 94, no. 4, pp. 465-495, 2009.

[2] L. Meunier, G. Chagnon, D. Favier, L. Orgéas, and P. Vacher, "Mechanical experimental characterisation and numerical modelling of an unfilled silicone rubber," Polymer Testing, vol. 27, no. 6, pp. 765-777, 2008.

[3] S.-H. Kim, E. A. Cherney, and R. Hackam, "Hydrophobic behavior of insulators coated with RTV silicone rubber," IEEE Transactions on Electrical Insulation, vol. 27, no. 3, pp. 610622, 1992.

[4] A. P. Pinheiro, "Architectural rehabilitation and sustainability of green buildings in historic preservation," HighTech and Innovation Journal, vol. 1, no. 4, pp. 172-178, 2020.

[5] C. Vargas-Elizondo, "On the role of ethics in shaping technology development," HighTech and Innovation Journal, vol. 1, no. 2, pp. 86-100, 2020.

[6] A. R. Khaloo, M. Dehestani, and P. Rahmatabadi, "Mechanical properties of concrete containing a high volume of tire-rubber particles," Waste Management, vol. 28, no. 12, pp. 2472-2482, 2008.

[7] N. N. Eldin and A. B. Senouci, "Rubber-tire particles as concrete aggregate," Journal of Materials in Civil Engineering, vol. 5, no. 4, pp. 478-496, 1993.

[8] Z. K. Khatib and F. M. Bayomy, "Rubberized Portland cement concrete," Journal of Materials in Civil Engineering, vol. 11, no. 3, pp. 206-213, 1999.

[9] G. Li, G. Garrick, J. Eggers, C. Abadie, M. A. Stubblefield, and S. Pang, "Waste tire fiber modified concrete," Composites Part B: Engineering, vol. 35, no. 4, pp. 305-312, 2004.

[10] J. Khan, A. Hussain, F. Haq, K. Ahmad, and K. Mushtaq, "Performance evaluation of modified bitumen with replaced percentage of waste cooking oil \& tire rubber with bagasse ash as modifier," Civil Engineering Journal, vol. 5, no. 3, pp. 587-596, 2019.

[11] M. Adom-Asamoah, J. B. Osei, and K. Adinkra-Appiah, "Structural characteristics of reinforced palm kernel shell concrete deep beams," Civil Engineering Journal, vol. 4, no. 7, p. $1477,2018$.

[12] A. A. Kadhim and H. M. K. Al-Mutairee, "An experimental study on behavior of sustainable rubberized concrete mixes," Civil Engineering Journal, vol. 6, no. 7, pp. 1273-1285, 2020.

[13] F. Hernández-Olivares, G. Barluenga, M. Bollati, and B. Witoszek, "Static and dynamic behaviour of recycled tyre rubber-filled concrete," Cement and Concrete Research, vol. 32, no. 10, pp. 1587-1596, 2002.

[14] R. Siddique and T. R. Naik, "Properties of concrete containing scrap-tire rubber - an overview," Waste Management, vol. 24, no. 6, pp. 563-569, 2004.

[15] A. M. Dessouki, N. H. Taher, and H. H. El-Nahas, "Preparation of composites of natural rubber latex-Portland cement for moulds," Polymer International, vol. 45, no. 4, pp. 339-346, 1998.

[16] H. A. Toutanji, "The use of rubber tire particles in concrete to replace mineral aggregates," Cement and Concrete Composites, vol. 18, no. 2, pp. 135-139, 1996.

[17] I. B. Topçu, "The properties of rubberized concretes," Cement and Concrete Research, vol. 25, no. 2, pp. 304-310, 1995.

[18] N. Segre and I. Joekes, "Use of tire rubber particles as addition to cement paste," Cement and Concrete Research, vol. 30, no. 9, pp. 1421-1425, 2000.

[19] H. A. Alasmari, B. H. Abu Bakar, and A. T. Noaman, "A comparative study on the flexural behaviour of rubberized and hybrid rubberized reinforced concrete beams," Civil Engineering Journal, vol. 5, no. 5, pp. 1052-1067, 2019.
[20] M. E. Komaki, A. Ghodrati Dolatshamloo, M. Eslami, and S. Heydari, "Ameliorating precast concrete curbs using rubber and nano material," Civil Engineering Journal, vol. 3, no. 2, pp. 105-110, 2017.

[21] K. Ha, "Innovative blade trailing edge flap design concept using flexible torsion bar and worm drive," HighTech and Innovation Journal, vol. 1, no. 3, pp. 101-106, 2020.

[22] S. Ghods, A. Kheyroddin, M. Nazeryan, S. M. Mirtaheri, and M. Gholhaki, "Nonlinear behavior of connections in RCS frames with bracing and steel plate shear wall," Steel and Composite Structures, vol. 22, no. 4, pp. 915-935, 2016.

[23] ASTM C 150-07, Standard Specification for Portland Cement, ASTM, West Conshohocken, PA, USA, 2020.

[24] American Concrete Institute, Standard Practice for Selecting Proportions for Normal, Heavyweight and Mass Concrete, pp. 1-91, American Concrete Institute, Farmington Hills, MI, USA, 2002.

[25] A. Khaloo, E. M. Raisi, P. Hosseini, and H. Tahsiri, "Mechanical performance of self-compacting concrete reinforced with steel fibers," Construction and Building Materials, vol. 51, pp. 179-186, 2014.

[26] ASTM C 143, Standard Method of Test for Slump of Hydraulic Cement Concrete, ASTM, West Conshohocken, PA, USA, 2020.

[27] ASTM C138/C138M-17a, Standard Test Method for Density (Unit Weight), Yield, and Air Content (Gravimetric) of Concrete, ASTM, West Conshohocken, PA, USA, 2020. 